\title{
How Statistical Analysis Tools Can Be Used to Effectively Plan and Execute a Strategic Plan for an Organization
}

Brian J. Galli, Long Island University, USA

iD https://orcid.org/0000-0001-9392-244X

\begin{abstract}
Pre-existing literature does not show how these variables, their concepts, and models help in strategic planning, which has resulted in a research gap. Thus, this study addresses the most current variables, their concepts, and models within operations and project management. With a design-scienceinvestigate strategy, the authors approve a valuable growth reveal for reasonable and hypothetical application. Thus, they create a suitable assessment model to fill the research void, as well as to contribute to the engineering field by improving the project success rates and helping with team communication.
\end{abstract}

\section{KEYWORDS}

Planning, Project Management, Statistics, Strategy

\section{INTRODUCTION}

\section{Background}

Data analysis and management skills are assets to every organization. In the age of big data, skills in machine learning, analytics, and statistics are essential sources of competitive advantage (Bryson, 2018; Zwikael, \& Smyrk, 2012; Xue, Baron, \& Esteban, 2017; Shenhar \& Levy, 2007). In an ideal situation, any profession or organization requires the combined skills of machine learning, analytics, and statistics (Carnall, 2018; David, David, \& David, 2017; Arumugam, 2016). However, it is difficult to find all three skills being used in one organization, which is why statistics skills are mostly preferred.

Furthermore, statistical analysis is involved with the transformation of raw data to information that can be used to inform decisions in every organization, which includes engineering. Statistics is involved with more than just the transformation of data (Chambers, 2017; Medina \& Medina, 2015; Hoon Kwak, \& Dixon, 2008; Galli, Kaviani, Bottani, \& Murino, 2017). Essentially, statistics is concerned more about using the right methods, tools, and tests to transform the data. Statistics uses mathematical models and science to fulfill objectives in the transformation of data, which is why statistical analysis tools are so important to engineering, the engineering management profession, and the research fields in general.

Although it is clear that statistical analysis tools are important in the transformation of data to information, it is still hardly considered that statistical analysis tools can be used to effectively execute

\section{DOI: 10.4018/IJAIE.20210101.oa3}

This article published as an Open Access article distributed under the terms of the Creative Commons Attribution License (http://creativecommons.org/licenses/by/4.0/) which permits unrestricted use, distribution, and production in any medium, provided the author of the original work and original publication source are properly credited. 
a strategic plan (Hand, 2017; Appelbaum, Kogan, \& Vasarhelyi, 2017; Ahern, Leavy, \& Byrne, 2014; Brown \& Eisenhardt, 1995; Schwedes, Riedel, \& Dziekan, 2017; Zhang et al., 2016). Similarly, there has been limited research focusing on the nexus between statistical analysis tools and the strategic plan of an organization, so this research seeks to establish the importance of statistical analysis tools.

\section{Problem Statement}

There is limited research focusing on the significance of statistical analysis tools in the planning and execution of strategies in an organization. However, this is despite the realization that data is an essential part of the organization and can actually be a source of competition. Overlooking the importance of statistical analysis tools leaves statisticians insufficiently involved in strategic planning (McLean, 2018; Xiong et al., 2017; Von Thiele Schwarz, 2017; Marcelino-Sádaba et al., 2014; Hartono, FN Wijaya, \& M. Arini, 2014). The statisticians and statistical analysis tools only come to the limelight when the organization is facing a crisis and needs to analyze data to diagnose the problem. Thus, this study seeks to shift the position and view of statistics and statistical analysis tools by making the tools a central feature in strategic planning in organizations. The study believes the following:

- Null hypothesis: Statistical analysis tools would not result in significant differences in the planning and execution of a strategic plan for an organization

- Alternative Hypothesis: Statistical analysis tools would result in significant differences in the planning and execution of a strategic plan for an organization

The study features original research focusing on the significance of statistical analysis tools in the strategic planning of an organization. Also, the study seeks to collect original data on the perception of organizations with respect to how they feel about statistical analysis tools in strategic planning. No part of the research will be drawn from any other documented information, whether published or unpublished. Any information drawn from any other source will be duly cited and acknowledged.

\section{Research Objective}

Literature may depict how important the variables, their concepts, and models can be within project management and performance, but there is a research gap that has developed. Few sources address how these variables, their concepts, and models cause project management and performance to progress smoothly. As a result, this research highlights the research gaps about these variables, their concepts, and models ad an assessment of the elements and applications. Thus, the study reveals how the variables are alike and different, which will allow the proposal of a framework that depicts the best practices of these variables. Such a "universal" framework can apply to every aspect within projects, operations, and performance, as well as to all types of organizations. This study will also offer answers to commonly asked questions from experts on these variables, such as how to best use them to achieve project management and performance objectives. These answers will be evidencebased, and the findings can become a platform for future research on these variables, their concepts, and models.

\section{Managerial Relevance}

An engineering manager is tasked with decision-making situations. In the future of project management and engineering, decision-making will become even more important. Thus, this study addresses the future of decision-making for an engineering management practitioner to understand how this applies to engineering management. Also, this study will address ways for engineering managers to account for decision-making during their operations, throughout the project management lifecycle, and within various project management environments. The implications of these findings are 
described and explained in reference to organizational levels, such as the corporate level and the managerial level. Finally, the conclusions are applicable to the engineering management practitioner for effectively capitalizing on the variables, concepts, models, and relationships at various levels of project environments and operations.

\section{Originality}

With study, the objective is to add and further develop information in literature about the effectiveness of these variables, their concepts, and models. Additionally, any similarities and differences within the assessment tools will be assessed. There is data from other studies that share this paper's hypotheses, which was used for this paper. Various research perspectives are also utilized to offer new problemsolving ideas for current problems. This study first uses a strategy of design-science-investigate. Then, it endorses a growth reveal to apply both reasonably and hypothetically. Finally, a sufficient assessment model is created from these variables, their concepts, and models.

As a response to the examination question, the evaluation instruments are highlighted and reviewed. Also, there is an outline for the development models. The outcomes of the meetings are outlined in the analysis, and the conclusion addresses preliminary discovery, ideas for arranging investigative limitations, and approaches for future studies.

In the findings, the benefits of utilizing the variables, their concepts, and models are explained. However, this study also addresses the limitations of not considering performance and sustainability. With true-to-life examples, this study shows the need to apply these theories in both theory and in practice.

\section{Organizational \& Managerial Contribution \& Relevance}

Since there is a research gap, this study focuses on the variables, their concepts, models, and their relationships to also propose a unified framework. The results can be applied to multiple subjects in the business world to learn the advantages and disadvantages of these variables, concepts, and models. Furthermore, this study reveals new perspectives to these factors under study. With this knowledge, a practitioner can benefit quite a bit by learning more effective ways to utilize these variables and their relationship.

\section{Contribution To The Field \& Profession of Industrial Engineering}

Additionally, this study contributes to Industrial Engineering (IE) research by speeding up the work process for an engineer. With this study, engineers can find ways to organize and maintain the system with current technology. Engineers will also save on many resources, such as money, time, energy, and work hours, which will allow them to complete their tasks more quickly.

The information in this study is clearly worded for any reader to understand (i.e., industrialists) the effectiveness of these variables, their concepts, and models. It also features a clear theoretical framework that contributes information to make this study a future reference. Clearly, the information within this study can help the IE profession and research field to find ways to edge out the competition.

\section{Paper Organization}

The following sections in this study are organized into specific sections. In section two, current literature undergoes a high-level literature review. Then, section three addresses the research methodology that was used. In section four, there are the findings and analysis. Finally, section five summarizes the implications for the practitioner, gives future research ideas, shows the limitations, and closes with some general conclusions. 


\section{LITERATURE REVIEW}

A quick online search of statistical analysis tools reveals that there is a shortage of research focusing on the subject. This is an indication of two possible factors. First, statistical tools may not be considered important in the strategic planning and strategy execution processes. Secondly, it is possible that researchers may not have considered that there is a problem with applying statistical tools in strategic planning.

However, there is research on strategic planning that can be rather telling. According to Wolf and Floyd (2017); Galli \& Hernandez-Lopez (2018), while strategic planning research would be considered an indispensable stage, many organizations often failed to consider strategic planning research. Instead, many organizations are focused on setting goals. Wolf and Floyd (2017) indicated that the failure to consider strategic planning research was a primary reason why many strategic plans were wasted, even after using many resources. Also, Grant (2016); Lee et al. (2013) indicated that the use of statistical analysis tools in strategic planning was a contemporary idea, so traditional organizations have not been considering statistical analysis tools as necessary aspects of strategic planning. Montgomery (2017) also indicated that the rise of statistical analysis tools was as a result of the rise in big data and the realization that organizations can use big data for a strategic competitive advantage. Nonetheless, the concept appeared to have not gained traction or wide applications in strategic planning.

Furthermore, Haynes (2018); Gimenez-Espin (2013) consider statistical analysis tools as complex necessities in planning. Organizations and governments can no longer succeed in planning and executing plans without the use of data, which places the role of statistical tools at the center of all planning. According to Akpolat (2017); Galli and Kaviani (2018); Galli (2018a), the rationale is that there is various data on virtually all aspects of life. Thus, using statistics in the government and business organizations can almost accurately predict any situation, including the need for infrastructural engineering over the next century. Papke-Shields and Boyer-Wright (2017); Galli (2018b); Galli (2018c) indicate that no planning should ever be conducted without due consideration of data, machine learning, analytics, and the use of statistical analysis tools.

With this literature review, it is evident that there is not much research focusing on the nexus between statistical analysis tools and strategic planning in government and business organizations. However, the big data revolution, the rise of machine learning, and the rise of analytics are making statistical analysis tools increasingly important (Yandell, 2017; Al-Kadeem, et al., 2017a; Andersen, 2014; Badi \& Pryke, 2016; Besner \& Hobbs, 2012). Future organizations will succeed on the back of the accurate statistical analysis of data. This makes statistical analysis tools indispensable, thereby justifying an accelerated investment in research focusing on statistical analysis tools for strategic decision-making. In the rest of this research, the focus will be on understanding how organizations perceive the use of statistical analysis tools.

\section{RESEARCH METHODOLOGY}

\section{Literature Review Research Approach}

Essentially, there are two steps that have been taken to perform the literature review. First, it was required to search for relevant information, such as inputs from keywords. This approach did not have much of a structure to it. However, step two was more structured, as it was the review process. Databases and search strong were used, and the tables of contents were also searched through for two journals that were relevant to the study. 


\section{Part 1: Explorative and Unstructured Literature Review}

This study will reassess certain keywords, so publications that matched the keywords were examined. Thus, 31 journal articles and 7 books were found. Subsequently, the keywords were studied from the 38 publications to be used as search terms in part two of the literature review.

\section{Part 2: Structured Literature Review}

This structured and systematic approach applied review-conducting methods, which was found in other literature. The structured review has four phases: preparing and scoping, review planning, searching and assessing literature for selection, and assessing all selected literature.

In phase (1), the review scope highlighted research related to the project. Furthermore, marketing and strategic planning were deemed as key concepts in the studies, so this phase was expected to result in a sufficient amount of evidence.

Phase (2) of the structured review involved connecting other concepts to the keywords. This broadened the range of information to yield more results, such as the keywords, their connection, and their interaction. However, certain terms, such as success, evaluation, and impact, did not yield applicable results.

Thus, phase (3) resulted in a sufficient representation of results. Many databases, including ProQuest, Business Source Complete, Elsevier, and EBSCO, were used, which yielded 15 conference papers and 25 results. Overall, 40 results were compiled that contained conference and journal papers.

Subsequently, the tables of contents were sifted through for tier 1 and tier 2 journals. These journals were academic and practitioner-based and added information to the study, regardless of matching the keywords. Any journals that were selected would become the premier specialty journals for the keywords. Figure 1 (below) shows the three streams that were involved with the search and selection phase. With the three streams, the results were condensed to 42 publications. The selection process yielded between 24 and 18 results and featured triangulation methods. With the first selection, it was anticipated to discover if the resulting publications were connected to keywords and to this study. Inclusion and exclusion criteria that focused on the abstract were used for this evaluation, but some publications included the entire paper or the introduction.

For phase (4), information was organized into an inductive and deductive analysis. Then, a software package was used to document the information. The deductive analysis involved documenting the university and country of the authors, along with recommended categories. For the research genre, the possible documentations included "empirical research," "theory development," "research essays and literature reviews," or "other". Also, deductive coding was added by proving that the publications used theoretical frameworks, such as through a research-based view and contingency theory. It was also indicated whether or not the publication offered a model.

Furthermore, a grounded theory approach was used throughout the inductive analysis. This allowed some publications to be coded with open and selective codes. Since most of the publications were chosen based on the annual average number of citations, this provided balance for older publications. Vital literature reviews were also included, along with some current publications that offered relevant and applicable information for the keywords research.

As indicated by phase (4), the key themes were generated by assessing the list of open codes to assemble them into axial and selective codes. For parts 1 and 2 of the literature review, between April 2018 and August 2018 was the optimal time period because it correlated with interrelated research activities. Also, there was one last assessment for relevant materials and their overlap that was performed during this time.

As indicated by this selection of papers, there are key themes between the variables, concepts, and models that are shared, as seen through descriptive and trait perspectives. By performing a statistical analysis and by assessing other variables, this research gained significance. In Table 1 (below), the 42 studies are identified, as well as the key themes. 
Figure 1. Research approach for literature review

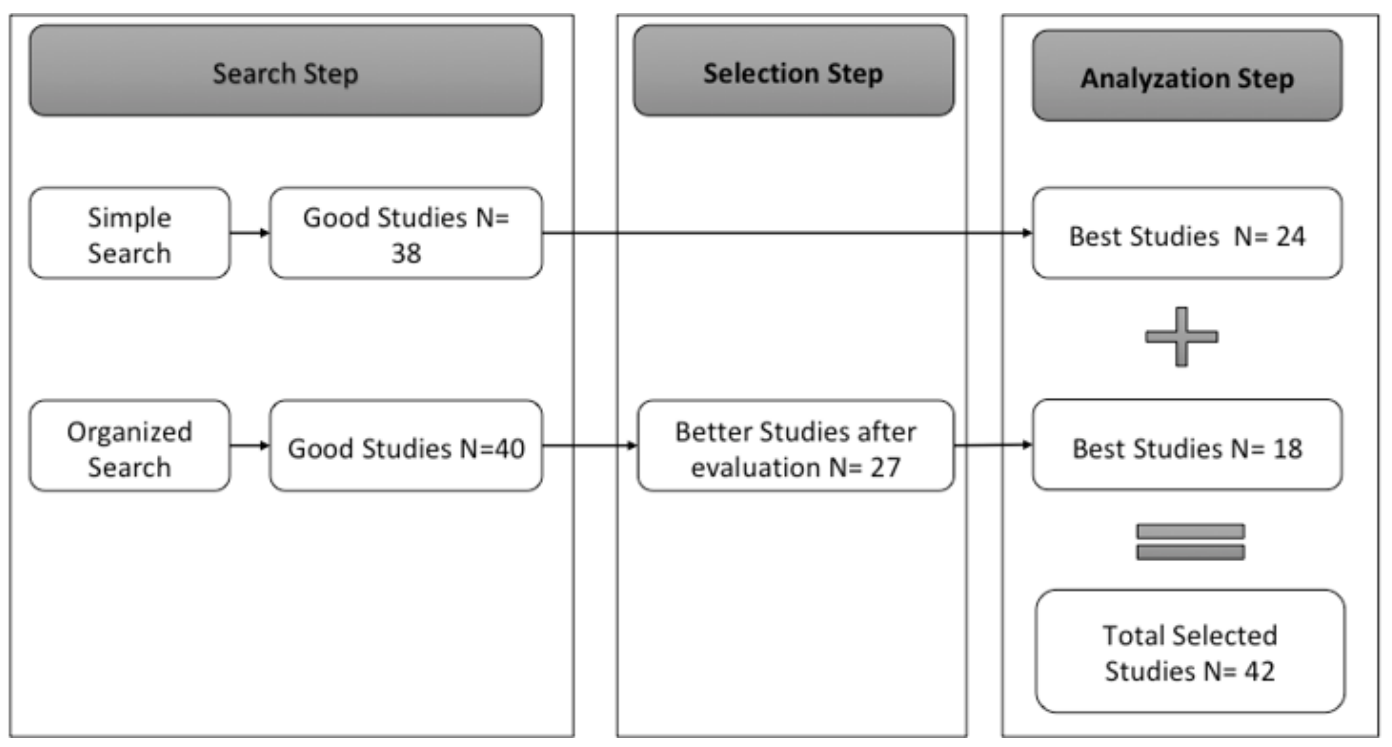

Examining the 42 studies has shown that the keywords were evaluated with a variety of statistical methods. These methods were also from relational and causal perspectives, so the research conclusions became more valuable. In Table 2 (below), the statistical methods that were used for 42 studies are summarized. Additionally, Table 3 (below) summarizes the number of factors/variables that were studied in the journals.

The next section features the research findings, which are illustrated based on upcoming themes or topics in later sections.

\section{FINDINGS}

The study finds that the application of statistical analysis tools in strategic planning would significantly improve strategic decision-making. Essentially, through the analysis of data with statistical tools, decision-makers can fully understand the environment within which strategic plans are designed. Similarly, the research finds that with statistical analysis tools, the decision-makers can identify trends in data, can determine factors (i.e., sustainability), and can identify problems and causes of concerns while preparing strategic plans.

Clearly, statistical analysis tools are important for information processing. Significant differences are notable where statistical analysis tools are used to analyze problems, as compared to instances where there is no accurate data analysis for decision-making (Cranmer et al., 2017; Svejvig \& Andersen, 2015; Todorović et al., 2015; Usman Tariq, 2013; Xue, Baron, \& Esteban, 2016; Yun et al., 2016; Winter et al., 2006a). Also, statistical analysis tools provide the decision-makers with data that can accurately design contingency plans if the strategic plans face challenges.

Business organizations and government entities have realized the importance of statistical tools. Particularly, the government and business organizations have realized the importance of using data to drive strategy. These factors are important in ensuring that the businesses and government organizations focus on the most important aspects of the business (Gunasekaran et al., 2017; Cova $\&$ Salle, 2005; Burnes, 2014; Detert, 2000). The implications are that policy and strategy are guided by data, which makes statistical analysis tools. 


\begin{tabular}{|c|c|}
\hline Theme \#1 & Theme \#2 \\
\hline $\begin{array}{l}\text { Ahern, Leavy, \& Byrne, (2014). } \\
\text { Appelbaum, Kogan, \& Vasarhelyi, (2017). } \\
\text { Arumugam, (2016). } \\
\text { Carnall, (2018). } \\
\text { Cova, \& Salle (2005). } \\
\text { David, David, \& David, (2017). } \\
\text { Eskerod, \& Blichfeldt, (2005). } \\
\text { Galli, and Kaviani, (2018). } \\
\text { Galli, Kaviani, Bottani, \& Murino, (2017). } \\
\text { Hartono, FN Wijaya, \& M. Arini, (2014). } \\
\text { Montgomery, (2017). } \\
\text { Xue, Baron, \& Esteban, (2016). } \\
\text { Xue, Baron, \& Esteban, (2017). } \\
\text { Andersen, (2014). } \\
\quad \text { Schwedes, Riedel, \& Dziekan, (2017). }\end{array}$ & $\begin{array}{l}\text { Al-Kadeem, Backar, Eldardiry, \& Haddad, (2017a). } \\
\text { Badi, \& Pryke, (2016). } \\
\text { Haynes, (2018). } \\
\text { Kerzner \& Kerzner, (2017). } \\
\text { Medina, \& Medina, (2015). } \\
\text { Milner, (2016). } \\
\text { Parast, (2011). } \\
\text { Parker, Parsons, \& Isharyanto, (2015). } \\
\text { Sharon, Weck \& Dori, (2013). } \\
\text { Shenhar, \& Levy, (2007). } \\
\text { Yun, et al. (2016). } \\
\text { Gimenez-Espin, (2013). } \\
\text { Hoon Kwak, \& Dixon, (2008). } \\
\text { Sutherland, (2004). } \\
\text { Yandell, (2017). }\end{array}$ \\
\hline Theme \#3 & Theme \#4 \\
\hline $\begin{array}{l}\text { Bryson, (2018). } \\
\text { Cranmer et al., (2017). } \\
\text { Detert, (2000). } \\
\text { Easton, \& Rosenzweig, (2012). } \\
\text { Galli, (2018c). } \\
\text { Galli, \& Hernandez - Lopez, (2018). } \\
\text { Gunasekaran et al., (2017). } \\
\text { Svejvig, \& Andersen, (2015). } \\
\text { Todorović et al. (2015). } \\
\text { Labedz, \& Gray, (2013). } \\
\text { Lee et al. (2013). } \\
\text { McLean, (2018). } \\
\text { Summers et al., (2018). } \\
\text { Usman Tariq, (2013). } \\
\text { Von Thiele Schwarz, (2017). } \\
\text { Wolf \& Floyd, (2017). } \\
\quad \text { Zwikael, \& Smyrk, (2012). }\end{array}$ & $\begin{array}{l}\text { Akpolat, (2017). } \\
\text { Besner, \& Hobbs, (2012). } \\
\text { Brown, \& Eisenhardt, (1995). } \\
\text { Burnes, (2014). } \\
\text { Chambers, (2017). } \\
\text { Galli, (2018a). } \\
\text { Galli, (2018b). } \\
\text { Grant, (2016). } \\
\text { Xiong et al. (2017). } \\
\text { Winter, et al. (2006a). } \\
\text { Loyd, (2016). } \\
\text { Marcelino-Sádaba et al. (2014). } \\
\text { Nagel, (2015). } \\
\text { Papke-Shields, \& Boyer-Wright, (2017). } \\
\text { Papadopoulos et al., (2017). } \\
\text { Wang, Kung, \& Byrd, (2018). } \\
\quad \text { Zhang, Bao, Wang, \& Skitmore, (2016). }\end{array}$ \\
\hline
\end{tabular}

Over the years, statistical analysis tools were mainly used in research fields. According to Papadopoulos et al. (2017); Easton \& Rosenzweig (2012); Eskerod \& Blichfeldt (2005), a strong distinction has been maintained between the uses of statistical analysis tools for research fields and the applications in business. These aspects have been critical in influencing the direction and importance of statistics. It is only until recently that the discovery of big data became an important driver of policy and strategy decisions (Brzezińska, 2018; Labedz \& Gray, 2013; Loyd, 2016; Milner, 2016; Sutherland, 2004). Then, statistics became the gateway to making informed decisions in both business and government agencies.

Though this study found a number of considerable challenges to using statistics in strategic planning, the lack of a data analysis culture in strategic planning is considered a major factor. The rise of big data complicates the processes of statistics with an increasing demand on the higher computing power for the statistical models, as well as an increasingly high number of variables for analysis in every decision (Wang, Kung, \& Byrd, 2018; Nagel, 2015; Parast, 2011; Parker, Parsons, \& Isharyanto, 2015; Sharon, Weck, \& Dori, 2013). These aspects demonstrate the possible inadequacy of available skills. To match the big data developments and statistical analysis tools, the further development of skills in statistics must be emphasized. 
Table 2. Systematic Analysis Results by Statistical Analysis Method

\begin{tabular}{|c|c|c|}
\hline $\begin{array}{l}\text { Statistical } \\
\text { Method }\end{array}$ & $\begin{array}{l}\text { Number of Articles } \\
\text { (Frequency) }\end{array}$ & Author(s) \\
\hline Regression & $17 \quad(25.76 \%$ of total articles $)$ & $\begin{array}{l}\text { Akpolat, (2017). } \\
\text { Bryson, (2018). } \\
\text { Chambers, (2017). } \\
\text { Cranmer et al., (2017). } \\
\text { Cova, \& Salle, (2005). } \\
\text { David, David, \& David, (2017). } \\
\text { Detert, (2000). } \\
\text { Easton, \& Rosenzweig, (2012). } \\
\text { Galli, Kaviani, Bottani, \& Murino, (2017). } \\
\text { Gimenez-Espin, (2013). } \\
\text { Loyd, (2016). } \\
\text { McLean, (2018). } \\
\text { Montgomery, (2017). } \\
\text { Summers et al., (2018). } \\
\text { Sutherland (2004). } \\
\text { Xue, Baron,\& Esteban, (2017). } \\
\quad \text { Zwikael, \& Smyrk, (2012). }\end{array}$ \\
\hline ANOVA & $12 \quad(18.18 \%$ of total articles $)$ & $\begin{array}{l}\text { Ahern, Leavy, \& Byrne, (2014). } \\
\text { Appelbaum, Kogan, \& Vasarhelyi, (2017). } \\
\text { Brown, \& Eisenhardt, (1995). } \\
\text { Galli, (2018b). } \\
\text { Galli, (2018c). } \\
\text { Gunasekaran et al., (2017). } \\
\text { Haynes, (2018). } \\
\text { Nagel, (2015). } \\
\text { Papke-Shields, \& Boyer-Wright, (2017). } \\
\text { Xiong, Zhao, Yuan, \& Luo, (2017). } \\
\text { Yandell, (2017). } \\
\quad \text { Yun, et al. (2016). }\end{array}$ \\
\hline Q-Test & $22 \quad(18.18 \%$ of total articles $)$ & $\begin{array}{l}\text { Arumugam, (2016). } \\
\text { Badi, \& Pryke, (2016). } \\
\text { Carnall, (2018). } \\
\text { Hoon Kwak, \& Dixon, (2008). } \\
\text { Grant, (2016). } \\
\text { Kerzner \& Kerzner, (2017). } \\
\text { Labedz, \& Gray, (2013). } \\
\text { Parker, Parsons, \& Isharyanto, (2015). } \\
\text { Papadopoulos et al., (2017). } \\
\text { Schwedes, Riedel, \& Dziekan, (2017). } \\
\text { Usman Tariq, (2013). } \\
\quad \text { Von Thiele Schwarz, (2017). }\end{array}$ \\
\hline t-Test & $11 \quad(16.67 \%$ of total articles $)$ & $\begin{array}{l}\text { Andersen, (2014). } \\
\text { Besner, \& Hobbs, (2012). } \\
\text { Burnes, (2014). } \\
\text { Eskerod, \& Blichfeldt, (2005). } \\
\text { Galli, (2018a). } \\
\text { Winter et al. (2006a). } \\
\text { Hartono, FN Wijaya, \& M. Arini, (2014). } \\
\text { Lee, Lapira, Bagheri, \& Kao, (2013). } \\
\text { Sharon, Weck, \& Dori, (2013). } \\
\text { Shenhar, \& Levy, (2007). } \\
\quad \text { Zhang et al. (2016). }\end{array}$ \\
\hline Chi-Square Test & $12 \quad(18.18 \%$ of total articles $)$ & $\begin{array}{l}\text { Al-Kadeem et al. (2017a). } \\
\text { Galli, and Kaviani, (2018). } \\
\text { Galli, \& Hernandez - Lopez, (2018). } \\
\text { Marcelino-Sádaba et al. (2014). } \\
\text { Medina, \& Medina, (2015). } \\
\text { Milner, (2016). } \\
\text { Parast, (2011). } \\
\text { Svejvig, \& Andersen, (2015). } \\
\text { Todorović et al. (2015). } \\
\text { Wang, Kung, \& Byrd, (2018). } \\
\text { Wolf \& Floyd, (2017). } \\
\quad \text { Xue, Baron, \& Esteban, (2016). }\end{array}$ \\
\hline
\end{tabular}


Table 3. Systematic Analysis Results by Number of Variables Studied

\begin{tabular}{|c|c|c|}
\hline $\begin{array}{l}\text { No. Factors } \\
\text { Studied }\end{array}$ & Number of Articles (Frequency) & Author(s) \\
\hline 1 & $13 \quad(19.70 \%$ of total articles $)$ & $\begin{array}{l}\text { Andersen, (2014). } \\
\text { Besner, \& Hobbs, (2012). } \\
\text { David, David, \& David, (2017). } \\
\text { Galli, (2018b). } \\
\text { Lee et al. (2013). } \\
\text { Medina, \& Medina, (2015). } \\
\text { Montgomery, (2017). } \\
\text { Nagel, (2015). } \\
\text { Papke-Shields, \& Boyer-Wright, (2017). } \\
\text { Sutherland, (2004). } \\
\text { Von Thiele Schwarz, (2017). } \\
\text { Wang, Kung, \& Byrd, (2018). } \\
\quad \text { Yun, et al. (2016). }\end{array}$ \\
\hline 2 & $8 \quad(12.12 \%$ of total articles $)$ & $\begin{array}{l}\text { Akpolat, (2017). } \\
\text { Al-Kadeem et al. (2017a). } \\
\text { Brown, \& Eisenhardt, (1995). } \\
\text { Cranmer et al., (2017). } \\
\text { Galli, \& Hernandez - Lopez, (2018). } \\
\text { Shenhar, \& Levy, (2007). } \\
\text { Summers et al., (2018). } \\
\quad \text { Xue, Baron, \& Esteban, (2016). }\end{array}$ \\
\hline 3 & $15 \quad(22.73 \%$ of total articles $)$ & $\begin{array}{l}\text { Arumugam, (2016). } \\
\text { Badi, \& Pryke, (2016). } \\
\text { Eskerod, \& Blichfeldt, (2005). } \\
\text { Galli, Kaviani, Bottani, \& Murino (2017). } \\
\text { Gimenez-Espin, (2013). } \\
\text { Gunasekaran et al., (2017). } \\
\text { Kerzner \& Kerzner, (2017). } \\
\text { Loyd, (2016). } \\
\text { Marcelino-Sádaba, et al. (2014). } \\
\text { McLean, (2018). } \\
\text { Papadopoulos et al., (2017). } \\
\text { Svejvig, \& Andersen, (2015). } \\
\text { Usman Tariq, (2013). } \\
\text { Winter et al. (2006a). } \\
\quad \text { Zhang et al. (2016). }\end{array}$ \\
\hline 4 & $11 \quad(16.67 \%$ of total articles $)$ & $\begin{array}{l}\text { Ahern, Leavy, \& Byrne, (2014). } \\
\text { Bryson, (2018). } \\
\text { Detert, (2000). } \\
\text { Easton, \& Rosenzweig, (2012). } \\
\text { Galli, (2018a). } \\
\text { Haynes, (2018). } \\
\text { Hoon Kwak, \& Dixon, (2008). } \\
\text { Labedz, \& Gray, (2013). } \\
\text { Parast, (2011). } \\
\text { Todorović et al. (2015). } \\
\quad \text { Zwikael, \& Smyrk, (2012). }\end{array}$ \\
\hline 5 & (13.64\% of total articles) & $\begin{array}{l}\text { Burnes, (2014). } \\
\text { Carnall, (2018). } \\
\text { Chambers, (2017). } \\
\text { Cova, \& Salle, (2005). } \\
\text { Galli, (2018c). } \\
\text { Grant, (2016). } \\
\text { Sharon, Weck \& Dori, (2013). } \\
\text { Wolf \& Floyd, (2017). } \\
\quad \text { Xue, Baron, \& Esteban, (2017). }\end{array}$ \\
\hline 6 & (12.12\% of total articles) & $\begin{array}{l}\text { Appelbaum, Kogan, \& Vasarhelyi, (2017). } \\
\text { Galli, and Kaviani, (2018). } \\
\text { Hartono, FN Wijaya, \& M. Arini, (2014). } \\
\text { Milner, (2016). } \\
\text { Parker, Parsons, \& Isharyanto, (2015). } \\
\text { Schwedes, Riedel, \& Dziekan, (2017). } \\
\text { Yandell, (2017). } \\
\quad \text { Xiong et al. (2017). }\end{array}$ \\
\hline
\end{tabular}


Lastly, the study asserts the importance of establishing a data analytics department in every organization. The goal of establishing such a department is to strategically position statistics as core functions of the business organizations. The findings of the study consider that it is only by treating statistics as main functions in the organization that statistical analysis tools will gain a commonplace in the strategic planning table. Statistics must be treated with the same attitude as the finance department, marketing department, or any other major function in the business. The realization that data will be a source of future competitive advantage should provide incentives for better applying statistics to the decision-making table.

Furthermore, the findings in this research are consistent with the grounded view that, despite its importance, statistical analysis is hardly applied by businesses in strategic planning and execution. However, the big data wave dictates that business organization cannot continue to ignore the importance of statistical analysis tools, considering that big data can be a source of competitive advantage. Also, the findings are applicable to all industries, including industrial engineering and information systems industries. In the latter, the knowledge in statistical analysis tools, along with aspects of optimization, improves planning for resources on every unit. This is because the business can combine the power of engineering with other data to make decisions about business performance, as well as the performance of the markets. By using data, industrial engineering improves processes and functions, eliminates waste, and results in the overall efficiency of operations.

\section{DISCUSSION}

\section{Organizational Implications}

According to this research, these variables, their concepts, and models are vital aspects of business projects and project management. Furthermore, this approach can lead to teams gaining certain skills for meeting company goals, which is better than investing in any current technology. Primarily, the results encourage strategic planning and a top-down and bottom-up leadership style, mostly for project management, operations management, and process improvement.

Furthermore, this study reveals that current project management and operational performance issues are rooted in poor leadership skills. A bottom line approach only focuses on profits and costs, which leads to short-term results. Thus, managing multiple elements of an organization, such as operations, project management, and financials, will lead to long-term results in every department.

\section{Managerial \& Team Implications}

Several implications are derived from this study. Firstly, the results examine the variables, concepts, models, and relationship in a new way to fill a research void. These concepts can directly affect a business' performance and effectiveness, so this information must not be ignored. Secondly, this study can provide an outline on projects and performances because it shows the relationship between these variables. Thus, management can become more effective with better mentoring or managerial components. Teams and organizations will improve on pinpointing and improving any shortcomings that hinder a project or department from reaching their goals. Thirdly, this study shows that there are many benefits to generating a more comprehensive training program to improve team and organizational performance and effectiveness. This study illustrates how project teams, project leadership, and organizational leadership can benefit with being trained on assessing the performance of a team, project, or business. Also, leadership methods can be adjusted by educating teams and leaders on how teams and projects affect the overall performance of a business. 


\section{Implications \& Applications To Fields of Project Management \& Engineering Management}

It has been made clear that these variables, their concepts, and models are important to projects. However, engineers and technical professions are important, as well. The expectations of an engineer have changed, as it once was required to use technology and math for problem-solving. Now, an engineer is expected to give economically viable solutions by problem-solving with technology and math. Engineering decisions can benefit from these variables, their concepts, and models because a product must profitable to lead to a rise in profits and performance. Thus, engineers should be exposed to business management and maturity models to benefit their investors.

Management and engineering go hand-in-hand, as they are both derived from scientific notions. This study takes an engineering perspective in describing these methods. It also emphasizes pure engineering filed techniques, including budgeting, equipment, and purchasing material. In this study, engineers and project managers can find many decision-making methods for engineering problems, as well as for screening projects for viability.

The IE/EM profession and research field rely on project management and operational performance because lean thinking is not always the answer. These variables, their concepts, and models produce a new IE/EM environment, but the structural orientation of a scope can lead to those within the IE/ EM field to create the scopes of interest that are needed at any level. In other words, there must be a more tactical method to generating the proper performance, so these variables, their concepts, and models have been implemented with the given scopes.

Also, stakeholders can gain important information from this study. System engineers, project managers, and other IE/EM experts can find information about applying maturity to project management. Stakeholders can even be inspired to best utilize the roles of system engineering and project management for optimal success.

Using systems thinking along with new product development can make products more marketable. With this study, the field can find ways for small businesses to make new products, even without multiple established processes. For the study, the product in question is only the second product from the specific company.

\section{CONCLUSION}

\section{Future Research}

For future research several areas can be explored. Firstly, researchers can discover how the variables, concepts, models, and relationships perform within other industries. For example, the benefits and detriments of these variables in these other settings can be studied, as well as what affects these variables. Secondly, researchers can find ways to view these factors and their relationship, as organizational, strategic, or cultural perspectives can be explored. It is important to know how the variables, concepts, models, and their relationship are viewed from these different perspectives to know how culture, strategy, human resources, and operations affect the variables, as well.

\section{Limitations}

Finally, there are some research limitations that need to be addressed. First, the sample size was too small, which could lead to bias and validity issues. With a larger sample size, this would not be a limitation. Second, the key factors and their relationship were only assessed through a project environment, so the conclusions and analysis become too specific. It cannot be asserted that the findings can apply to supply chain management, operations management, or strategic management. Thus, the findings may not apply to other industries or managerial settings, so the information is a bit restricted. 


\section{General Conclusions}

Essentially, the study concluded that there is a significant difference between businesses that apply statistical analysis tools in strategic planning and those that do not. While only a small business has actually employed statistical analysis personnel, it is evident that the trend was quickly shifting towards big data analytics. Big data analytics are seen to give a competitive advantage by employing personnel with statistical analysis skills. The study concluded that application of statistical analysis tools improves both the planning and execution of the strategic plans. It is a move from blind planning to data-guided planning in the organization. Instead of anticipating issues without any form of evidence, businesses can use big data from multiple sources to determine trends and to help in planning operations with many details.

Finally, an important area of application for statistical analysis tools is in sensitivity analysis and contingency planning. While past businesses could hardly anticipate changing scenarios, the application of blockchain technologies results in a seismic shift in the prediction of scenarios, which enables the implementation of proper contingency plans if strategy plans are negatively affected. Note that by the power of data and statistical analysis, businesses can now predict longer periods of time. This was not possible in the past because many businesses were informed that they could not predict the future. However, this research recommends the full adoption of statistical analysis tools in the strategic planning room and in every other planning process. Considering the cost, business organizations can access statistical analysis tools by hiring in-house statisticians or by outsourcing statisticians. In the long run, it will be required to integrate statistical analysis tools in every process and function of the business. These aspects are critical in forming successful businesses that are ready for a future that is guided by data and exact science in business decision-making. Lastly, the study recommends the extension of current business optimization models into models that are sensitive to data and the higher number of models. This will improve the predictive and explanatory powers of the models, which will enable better and more informed decisions. Thus, there will be an increasing computing power of both machines and the statistical analysis tools. 


\section{REFERENCES}

Ahern, T., Leavy, B., \& Byrne, P. J. (2014). Complex project management as complex problem solving: A distributed knowledge management perspective. International Journal of Project Management, 32(8), 1371-1381. doi:10.1016/j.ijproman.2013.06.007

Akpolat, H. (2017). Six sigma in transactional and service environments. Routledge. doi:10.4324/9781315243030

Al-Kadeem, R., Backar, S., Eldardiry, M., \& Haddad, H. (2017a). Review on using system Dynamics in designing work systems of project organizations: Product development process case study. International Journal of System Dynamics Applications, 6(2), 52-70. doi:10.4018/IJSDA.2017040103

Andersen, E. S. (2014). Value creation using the mission breakdown structure. International Journal of Project Management, 32(5), 885-892. doi:10.1016/j.jpproman.2013.11.003

Appelbaum, D., Kogan, A., \& Vasarhelyi, M. A. (2017). Big Data and analytics in the modern audit engagement: Research needs. Auditing, 36(4), 1-27. doi:10.2308/ajpt-51684

Arumugam, V. A., Antony, J., \& Linderman, K. (2016). The influence of challenging goals and structured method on Six Sigma project performance: A mediated moderation analysis. European Journal of Operational Research, 254(1), 202-213. doi:10.1016/j.ejor.2016.03.022

Badi, S. M., \& Pryke, S. (2016). Assessing the impact of risk allocation on sustainable energy innovation (SEI): The case of private finance initiative (PFI) school projects. International Journal of Managing Projects in Business, 9(2), 259-281. doi:10.1108/IJMPB-10-2015-0103

Besner, C., \& Hobbs, B. (2012). The paradox of risk management; a project management practice perspective. International Journal of Managing Projects in Business, 5(2), 230-247. doi:10.1108/17538371211214923

Brown, S. L., \& Eisenhardt, K. M. (1995). Product development: Past research, present findings, and future directions. Academy of Management Review, 20(2), 343-378. doi:10.5465/amr.1995.9507312922

Bryson, J. M. (2018). Strategic planning for public and nonprofit organizations: A guide to strengthening and sustaining organizational achievement. John Wiley \& Sons.

Brzezińska, J. (2018). Statistical analysis of economic poverty in Poland using R. Econometrics, 22(2), 45-53. doi:10.15611/eada.2018.2.04

Burnes, B. (2014). Kurt Lewin and the planned approach to change: A re-appraisal. Journal of Management Studies, 41(6), 977-1002. doi:10.1111/j.1467-6486.2004.00463.x

Carnall, C. (2018). Managing change. Routledge. doi:10.4324/9781315122779

Chambers, J. M. (2017). Graphical Methods for Data Analysis: 0. Chapman and Hall/CRC.

Cova, B., \& Salle, R. (2005). Six key points to merge project marketing into project management. International Journal of Project Management, 23(5), 354-359. doi:10.1016/j.ijproman.2005.01.006

Cranmer, S. J., Leifeld, P., McClurg, S. D., \& Rolfe, M. (2017). Navigating the range of statistical tools for inferential network analysis. American Journal of Political Science, 61(1), 237-251. doi:10.1111/ajps.12263

David, M. E., David, F. R., \& David, F. R. (2017). The quantitative strategic planning matrix: A new marketing tool. Journal of Strategic Marketing, 25(4), 342-352. doi:10.1080/0965254X.2016.1148763

Detert, J. R., Schroeder, R. G., \& Mauriel, J. J. (2000). A framework for linking culture and improvement initiatives in organizations. Academy of Management Review, 25(4), 850-863. doi:10.5465/amr.2000.3707740

Easton, G. S., \& Rosenzweig, E. D. (2012). The role of experience in six sigma project success: An empirical analysis of improvement projects. Journal of Operations Management, 30(7), 481-493. doi:10.1016/j. jom.2012.08.002

Eskerod, P., \& Blichfeldt, B. S. (2005). Managing team entrees and withdrawals during the project life cycle. International Journal of Project Management, 23(7), 495-503. doi:10.1016/j.ijproman.2004.12.005 
Galli, B. (2018a). Application of system engineering to project management-How to view their relationship. International Journal of System Dynamics Applications, 7(4), 76-97. doi:10.4018/IJSDA.2018100105

Galli, B. (2018b). Can project management help improve lean six sigma? IEEE Engineering Management Review, 46(2), 55-64. doi:10.1109/EMR.2018.2810146

Galli, B. (2018c). Risks related to lean six sigma deployment and sustainment risks: How project management can help. International Journal of Service Science, Management, Engineering, and Technology, 9(3), 82-105. doi:10.4018/IJSSMET.2018070106

Galli, B., \& Hernandez-Lopez, P. (2018). Risks management in agile New Product Development project environments-A review of literature. International Journal of Risk and Contingency Management, 7(4), 37-67. doi:10.4018/IJRCM.2018100103

Galli, B., \& Kaviani, M. A. (2018). The impacts of risk on deploying and sustaining Lean Six Sigma initiatives. International Journal of Risk and Contingency Management, 7(1), 46-70. doi:10.4018/IJRCM.2018010104

Galli, B., Kaviani, M. A., Bottani, E., \& Murino, T. (2017). An investigation of shared leadership \& key performance indicators in Six Sigma projects. International Journal of Strategic Decision Sciences, 8(4), 1-45. doi:10.4018/IJSDS.2017100101

Gimenez-Espin, J. A.-J.-C., Jiménez-Jiménez, D., \& Martínez-Costa, M. (2013). Organizational culture for total quality management. Total Quality Management \& Business Excellence, 24(5-6), 678-692. doi:10.1080/ 14783363.2012.707409

Grant, R. M. (2016). Contemporary strategy analysis: Text and cases edition. John Wiley \& Sons.

Gunasekaran, A., Papadopoulos, T., Dubey, R., Wamba, S. F., Childe, S. J., Hazen, B., \& Akter, S. (2017). Big data and predictive analytics for supply chain and organizational performance. Journal of Business Research, 70, 308-317. doi:10.1016/j.jbusres.2016.08.004

Hand, D. J. (2017). Practical longitudinal data analysis. Routledge. doi:10.1201/9780203742372

Hartono, , \& Wijaya, , \& Arini. (2014). An empirically verified project risk maturity model: Evidence from Indonesian construction industry. International Journal of Managing Projects in Business, 7(2), $263-284$. doi:10.1108/IJMPB-03-2013-0015

Haynes, P. (2018). Complex policy planning: the government strategic management of the social care market. Routledge. doi:10.4324/9780429461613

Hoon Kwak, Y., \& Dixon, C. K. (2008). Risk management framework for pharmaceutical research and development projects. International Journal of Managing Projects in Business, 1(4), 552-565. doi:10.1108/17538370810906255

Labedz, C. S., \& Gray, J. R. (2013). Accounting for lean implementation in government enterprise: Intended and unintended consequences. International Journal of System Dynamics Applications, 2(1), 14-36. doi:10.4018/ ijsda.2013010102

Lee, J., Lapira, E., Bagheri, B., \& Kao, H. (2013). Recent advances and trends in predictive manufacturing systems in big data environment. Journal of Cleaner Production, 3(10), 45-55.

Loyd, N. (2016). Implementation of a plan-do-check-act pedagogy in industrial engineering education. International Journal of Engineering Education, 32(3), 1260-1267.

Marcelino-Sádaba, S., Pérez-Ezcurdia, A., Lazcano, A. M. E., \& Villanueva, P. (2014). Project risk management methodology for small firms. International Journal of Project Management, 32(2), 327-340. doi:10.1016/j. ijproman.2013.05.009

McLean, M. (2018). Understanding your economy: Using analysis to guide local strategic planning. Routledge. doi: $10.4324 / 9781351179065$

Medina, R., \& Medina, A. (2015). The competence loop: Competence management in knowledge-intensive, project-intensive organizations. International Journal of Managing Projects in Business, 8(2), 279-299. doi:10.1108/IJMPB-09-2014-0061 
Milner, C. D., \& Savage, B. M. (2016). Modeling continuous improvement evolution in the service sector: A comparative case study. International Journal of Quality and Service Sciences, 8(3), 438-460. doi:10.1108/ IJQSS-07-2016-0052

Montgomery, D. C. (2017). Design and analysis of experiments. John Wiley \& sons.

Nagel, R. (2015). Operational optimization: A lean six sigma approach to sustainability. Proceedings of the Water Environment Federation, 3(4), 1-12. doi:10.2175/193864715819556688

Papadopoulos, T., Gunasekaran, A., Dubey, R., \& Fosso Wamba, S. (2017). Big data and analytics in operations and supply chain management: Managerial aspects and practical challenges. Production Planning and Control, 28(11-12), 873-876. doi:10.1080/09537287.2017.1336795

Papke-Shields, K. E., \& Boyer-Wright, K. M. (2017). Strategic planning characteristics applied to project management. International Journal of Project Management, 35(2), 169-179. doi:10.1016/j.jproman.2016.10.015

Parast, M. M. (2011). The effect of Six Sigma projects on innovation and firm performance. International Journal of Project Management, 29(1), 45-55. doi:10.1016/j.jproman.2010.01.006

Parker, D. W., Parsons, N., \& Isharyanto, F. (2015). The inclusion of strategic management theories to project management. International Journal of Managing Projects in Business, 8(3), 552-573. doi:10.1108/ IJMPB-11-2014-0079

Schwedes, O., Riedel, V., \& Dziekan, K. (2017). Project planning vs. strategic planning: Promoting a different perspective for sustainable transport policy in European R\&D projects. Case Studies on Transport Policy, 5(1), 31-37. doi:10.1016/j.cstp.2016.08.006

Sharon, A., Weck, O. L., \& Dori, D. (2013). Improving project-product lifecycle management with model-based design structure matrix: A joint project management and systems engineering approach. Systems Engineering, 16(4), 413-426. doi:10.1002/sys.21240

Shenhar, A. J., \& Levy, O. (2007). Mapping the dimensions of project success. Project Management Journal, $28,5-13$.

Sutherland, S. (2004). Creating a culture of data use for continuous improvement: A case study of an Edison project school. The American Journal of Evaluation, 25(3), 277-293. doi:10.1177/109821400402500302

Svejvig, P., \& Andersen, P. (2015). Rethinking project management: A structured literature review with a critical look at the brave new world. International Journal of Project Management, 33(2), 278-290. doi:10.1016/j. ijproman.2014.06.004

Todorović, M. L., Petrović, D. Č., Mihić, M. M., Obradović, V. L., \& Bushuyev, S. D. (2015). Project success analysis framework: A knowledge-based approach in project management. International Journal of Project Management, 33(4), 772-783. doi:10.1016/j.jpproman.2014.10.009

Usman Tariq, M. (2013). A Six Sigma based risk management framework for handling undesired effects associated with delays in project completion. International Journal of Lean Six Sigma, 4(3), 265-279. doi:10.1108/ IJLSS-05-2013-0028

Von Thiele Schwarz, U. N.-H., Nielsen, K. M., Stenfors-Hayes, T., \& Hasson, H. (2017). Using kaizen to improve employee well-being: Results from two organizational intervention studies. Human Relations, 70(8), 966-993. doi:10.1177/0018726716677071 PMID:28736455

Wang, Y., Kung, L., \& Byrd, T. A. (2018). Big data analytics: Understanding its capabilities and potential benefits for healthcare organizations. Technological Forecasting and Social Change, 126, 3-13. doi:10.1016/j. techfore.2015.12.019

Winter, M., Andersen, E. S., Elvin, R., \& Levene, R. (2006a). Focusing on business projects as an area for future research: An exploratory discussion of four different perspectives. International Journal of Project Management, 24(8), 699-709. doi:10.1016/j.jproman.2006.08.005

Wolf, C., \& Floyd, S. W. (2017). Strategic planning research: Toward a theory-driven agenda. Journal of Management, 43(6), 1754-1788. doi:10.1177/0149206313478185 
Xiong, W., Zhao, X., Yuan, J.-F., \& Luo, S. (2017). Ex post risk management in public-private partnership infrastructure projects. Project Management Journal, 48(3), 76-89. doi:10.1177/875697281704800305

Xue, R., Baron, C., \& Esteban, P. (2016). Improving cooperation between systems engineers and project managers in engineering projects-towards the alignment of systems engineering and project management standards and guides. Proceedings of Joint Conference on Mechanical, Design Engineering \& Advanced Manufacturing, 24(2), 23-40.

Xue, R., Baron, C., \& Esteban, P. (2017). Optimizing product development in industry by alignment of the ISO/ IEC 15288 systems engineering standard and the PMBoK guide. International Journal of Product Development, 22(1), 65-80. doi:10.1504/IJPD.2017.085278

Yandell, B. (2017). Practical data analysis for designed experiments. Routledge. doi:10.1201/9780203742563

Yun, S., Choi, J., Oliveira, D. P., Mulva, S. P., \& Kang, Y. (2016). Measuring project management inputs throughout capital project delivery. International Journal of Project Management, 34(7), 1167-1182. doi:10.1016/j.ijproman.2016.06.004

Zhang, X., Bao, H., Wang, H., \& Skitmore, M. (2016). A model for determining the optimal project life span and concession period of BOT projects. International Journal of Project Management, 34(3), 523-532. doi:10.1016/j. ijproman.2016.01.005

Zwikael, O., \& Smyrk, J. (2012). A general framework for gauging the performance of initiatives to enhance organizational value. British Journal of Management, 23, S6-S22. doi:10.1111/j.1467-8551.2012.00823.x

Brian J. Galli holds a doctoral degree in Engineering Management from Old Dominion University. He also holds a Bachelors of Science in Industrial Engineering from Binghamton University and Masters of Science in Engineering Management from Missouri University of Science \& Technology. He works as an Assistant Professor of Management Engineering at Long Island University - Post. He also owns Apex Strategies, Ltd, a company that that specializes in continuous improvement consulting and training. He has over 9 years of experience in applying continuous improvement tools in many arenas. 